Baldwin, 33 South street, New York. The Hopkins and Dickinson M'f'g Co,, 76 Reade St., N. Y., and Darlington, N. J., have the exclusive specialty of metalined sliding door sheaves and builders' hardware generally. But these illustrations need not be extended.

\section{THE SUN.}

By Professor C. A. Young.

To the Editor of "SCIENCE."

DEAR SIR,-May I avail myself of the columns of your journal to correct a few serious errors which have come to light in my recent book on the Sun.

P. 16, near bottom.--The interval from the vernal equinox to the autumnal is 186 clays, instead of 184 , as stated. Of course the remaining part of the year is 179 days, not $\mathrm{r} 8 \mathrm{r}$.

P. 44. - The earth would fall to the sun in about two months, not four.

P. 240, 24I, and 279.- The candle power of the sun is given just four times too great. The figures printed express the number of candles which, distributed over the surface of an opaque globe, would give the same amount of light the sun does, each flame being considered as a small FLAT radiating surface. But this does not express the true ratio between the sun's light and that of a candle radiating freely in all directions.

P. 271.--In the formula for the number of calories of heat generated by the stoppage of a moving body, the denominator ought to be 8338 instead of 850 . The factor $g\left(9.8 \mathrm{I}^{\mathrm{m}}\right)$, having been accidentally omitted. In consequence, a few lines below, another 850 becomes $833^{8}$ also, and $300^{\circ}$ becomes about $30^{\circ}$

There are a number of other minor errors, which it is hardly worth while to notice here, though they will be corrected in the second edition.

C. A. YOUNG.

\section{To the Editor of "SCIENCE."}

A friend of mine who is a reliable observer relates an incident which forcibly illustrates the power of parental affection to overcome fear. The gentleman found a nest of young mice and removed them to the ground near by. The mother mouse made her appearance and carried away one of her young and while she was gone the gentleman took the remaining mice in his hand. When the mouse again appeared and could not find her young she seemed to hesitate a moment and then ran up the gentleman's clothes, took one of the young and carried it away. This was repeated until all the young were removed to a place of safety.

Springfield, MAss., Dec. 27, '8I.

\section{BOOKS RECEIVED.}

A Treatise on Comparative Embryology, by Francis M. Balfour, LL. D., F, R. S. Vol. II. Macmillan \& Co., New York, I88r.

An extended notice of this admirable work will appear later, we now simply announce that Messrs. Macmillan are ready to supply the second volume which completes the work, and we feel sure that every Biologist and Anatomist will avail himself of the mass of information included in Professor Balfour's book, which in competent hands must prove one of the most valuable aids to original work in this direction.

Elementary Lessons in Electricity and MaGNeTism, by Silvanus P. Thompson, Professor of Experimental Physics in University College, Bristol. Macmillan \& Co., Bond St. New York and London. Price $\$ 1.25$.

an Elementary Treatise on Electricity. By JAMES CLERK MAXWLiLI, Professor of Experimental
Physics in the University of Cambridge, England. Clarendon Press Series, Oxford, 188r. Price \$1.90.

Imported by Macmillan, Bond Street, New York. Students, and the many practical men who are now studying Electricity with a view to its application to the manufactures and arts, will find that these two books will exactly meet their requirements, in being comprehensive thoroughly practical and reliable. Those who cannot purchase both works, should commence with that by Professor Thompson, and follow with Professor Maxwell's as being more advanced.

The doctrine of the Conservation of Electricity, now growing into shape, but here first enumerated under that name, is thoroughly explained in Professor Thompson's book, and may be studied with profit by all interested in the science of electricity. This theory teaches us that we can neither create nor destroy electricity, though we may alter its distribution. According to this view all our electrical machines and batteries are merely instruments for altering the distribution of electricity by running it from one place to another, or for causing electricity, when accumulated or heaped together in one place, to do work in returning to its former level distribution.

Ideality in the Physical Sciences. By Benjamin Peirce. Messrs. Little, Brown \& Company. Boston.

This work by the late Professor Benjamin Peirce is an admirable illustration of the fact, that a man of individuality and sound judgment may pursue the highest scientific work and still find himself in harmony with the religious sentiments of his fellow man.

A great portion of this work is devoted to a review of past astronomical research, and will be read with interest as a reliable exposition written for those who require scientific work explained in simple language.

Photographic Exhibition.-The substitution of a film of dried gelatin for the thin layer of wet collodion, which the photographer formerly employed as a vehicle to retain the sensitive salts of silver in a suitable condition on his glass plate, has involved considerable alterations in the mechanical appliances used in photography. For out of doors work, or work away from home, the photographer no longer requires to carry what was practically a portable laboratory. Not having to "develop" his pictures on the spot, he need take with him neither dark tent nor chemicals. On the other hand, he must have some provision by which his store of dry plates can be placed, one after the other, in the camera and properly "exposed" without the risk of the slightest particle of light reaching their sensitive surface, other than the light properly directed upon them by the lens. As he wishes to carry an ample supply of plates with him, and as the glass plates themselves make an appreciable burden in a long walk, it is essential that the apparatus for carrying them should be as light as possible ; hence have arisen considerable improvement in the camera and its "slides." Again, the increased sensitiveness of the gelatin films makes it possible to give exposures shorter than can be affected by the hand uncapping and re-capping the lens; hence the invention of numerous "instantaneous shutters," by which exposures of a few hundredths of a second can be given, and pictures of moving objects readily secured. These are but instances of the many novel appliances which recent progress in photographic science has originated, and, besides these, there has been, during recent years, many and important improvements in the application of photography to the production of permanent illustrations for books and newspapers. All these varied applications of the art are to be illustrated by an exhibition of photographic appliances which the Council of the Society of Arts announce will be held during January and February next, in connexion with a course of Cantor lectures to be given before the Society by Capt. Abney. Full particulars of this exhibition are given in the Fournal of the Society of Arts for last week. 